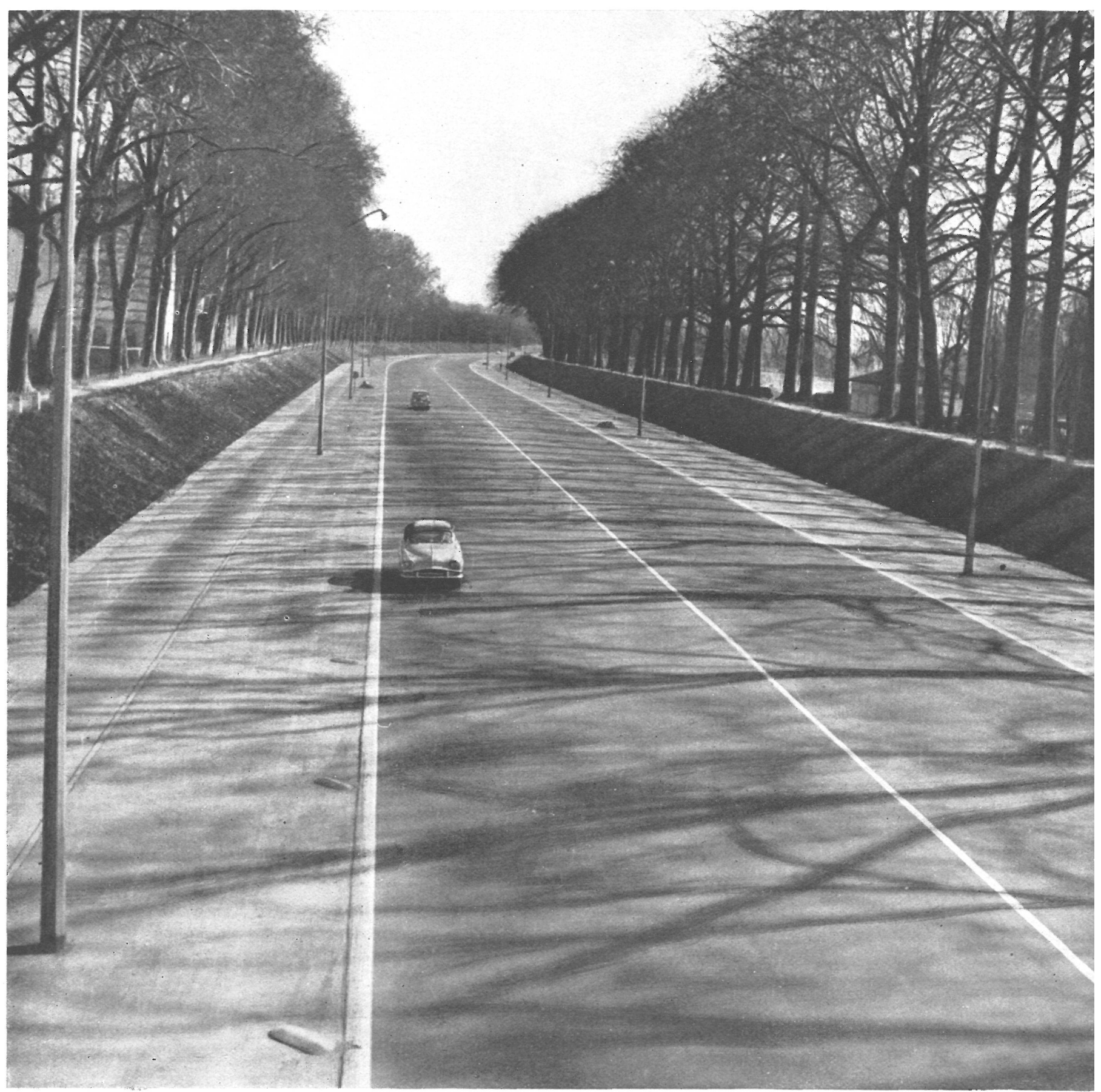

\title{
autopistas y aeródromos
}

GEORGES RODRÍGUEZ, ingeniero

S I N O P S I S

Estado actual, realización y proyectos de algunas de las pistas de aeródromos y grandes vías de circulación en Francia. El autor se extiende, además, en algunas consideraciones de ejecución, características específicas y ma. quinaria auxiliar potente. 
El aumento continuo de la circulación por carretera en la región parisina ha conducido a una casi saturación de tráfico. Si bien en menor escala, este mismo fenómeno se hace sentir en todo el país.

La solución de este gran problema depende más de las posibilidades económicas que de las técnicas, cada día más refinadas. En efecto, se sigue discutiendo de las cualidades del hormigón asfáltico y del cemento, pero la cuestión dominante se centra siempre sobre precios, ya que los créditos a este objeto son siempre insuficientes para las necesidades.

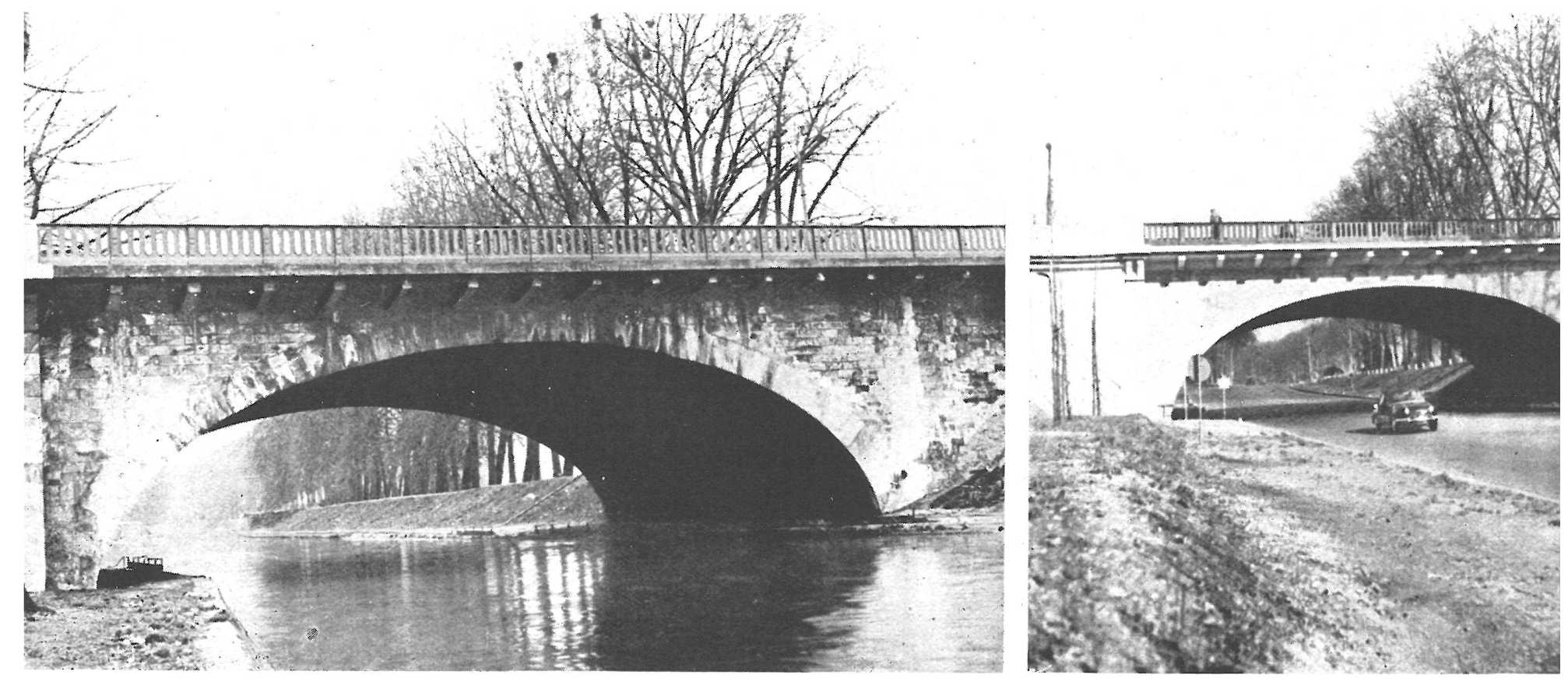

Las empresas constructoras francesas disponen de un material auxiliar potente y moderno, pero su equipo se inclina más a una ejecución rápida en pistas de aeropuertos y grandes vías que a la red secundaria de caminos estrechos, donde la conservación se hace sentir pesadamente.

Una forma de reducir los gastos consiste en programar, en colaboración con dos o tres departamentos limítrofes, lo que permite una producción en masa, económica, y con reducido número de cambios de la instalación de las grandes centrales de producción de materiales para el revestimiento.

Sirva de ejemplo a este fin lo sucedido con un equipo tipo completo Barber Greene, de 100 toneladas de rendimiento horario, empleado en la construcción de pistas en el aeropuerto de Niza.

El antiguo aeródromo de Niza hubo de ser ampliado debido a la insuficiencia de sus pistas. Con tal objeto se redactaron varios proyectos. Después de la guerra, las fuerzas aéreas aliadas llevaron la longitud de pista a $1.350 \mathrm{~m}$, y su anchura a $40 \mathrm{~m}$. Posteriormente, al pasar el campo a los servicios civiles, la pista se amplió a $1.700 \mathrm{~m}$, constituyendo un aeropuerto con plataforma de estacionamiento. El tráfico de 5.000 aviones y 34.000 pasajeros de 1946 pasó a 21.000 y 410.000 , respectivamente. Las puntas de verano rebasaron los 100 aparatos y 1.800 viajeros por día. A partir de entonces, este aeropuerto era el tercero de Francia, después de Orly, Le Bourget y en paridad con Marignane. Las grandes líneas internacionales hacen escala en este aeródromo actualmente.

Para poner las pistas e instalaciones del campo a tenor con las nuevas necesidades se redactó un nuevo programa de readaptación, que consistió en las obras siguientes: 
Relleno del canal de Saint Maurice. Compactación de la autopista.

a) construcción de una pista de $2.200 \mathrm{~m}$ de longitud, $60 \mathrm{~m}$ de anchura y capaz para aeronaves de 80 toneladas de peso, a razón de 35 toneladas de presión por rueda;

b) habilitación de una plataforma de estacionamiento, para 20 aviones, con una superficie total de $82.000 \mathrm{~m}^{2}$

c) construcción de $76.000 \mathrm{~m}^{2}$ de pistas de rodadura;

d) un edificio de dos plantas para las instalaciones técnicas de meteorología, radio, etc., $\mathrm{y}$

e) una nueva torre de mando de seis plantas.

Todas estas obras comprendían la primera parte del plan y debían estar terminadas en 1955. La segunda fase, a partir de esta fecha, consistió:

1) desviación de una carretera próxima para permitir la ampliación de terrenos y limpiar la zona de aproximación de la gran pista;

2) construcción de un dique, que permitiría ganar terreno hacia el mar para facilitar un alargamiento ulterior de la pista, y

3) una edificación en bloque, que constituiría un aerogaraje.

Suponiendo $1 / 10$ como equivalencia entre franco francés y peseta, el valor de estas obras de mejora se estimó a $400 \mathrm{mi}$ llones de pesetas.

En la preparación del terreno había una zona pantanosa, que hubo que rellenar con una capa de hasta $2 \mathrm{~m}$ de espesor. Los materiales de relleno se sacaron, por dragado, del lecho del río Var, en cantidad total de 500.000 metros cúbicos, y se colocaron a razón de 4.000 por día.
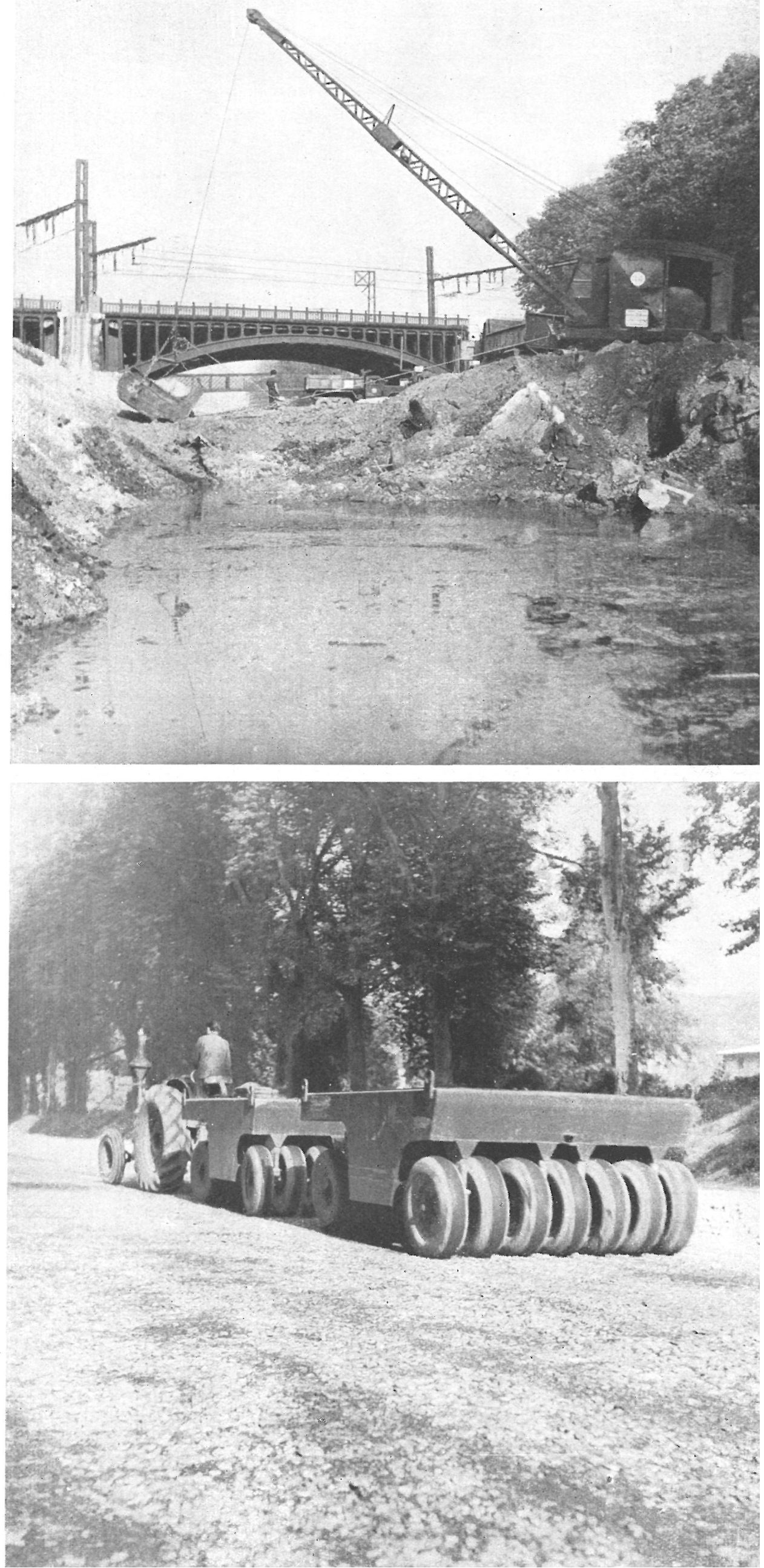


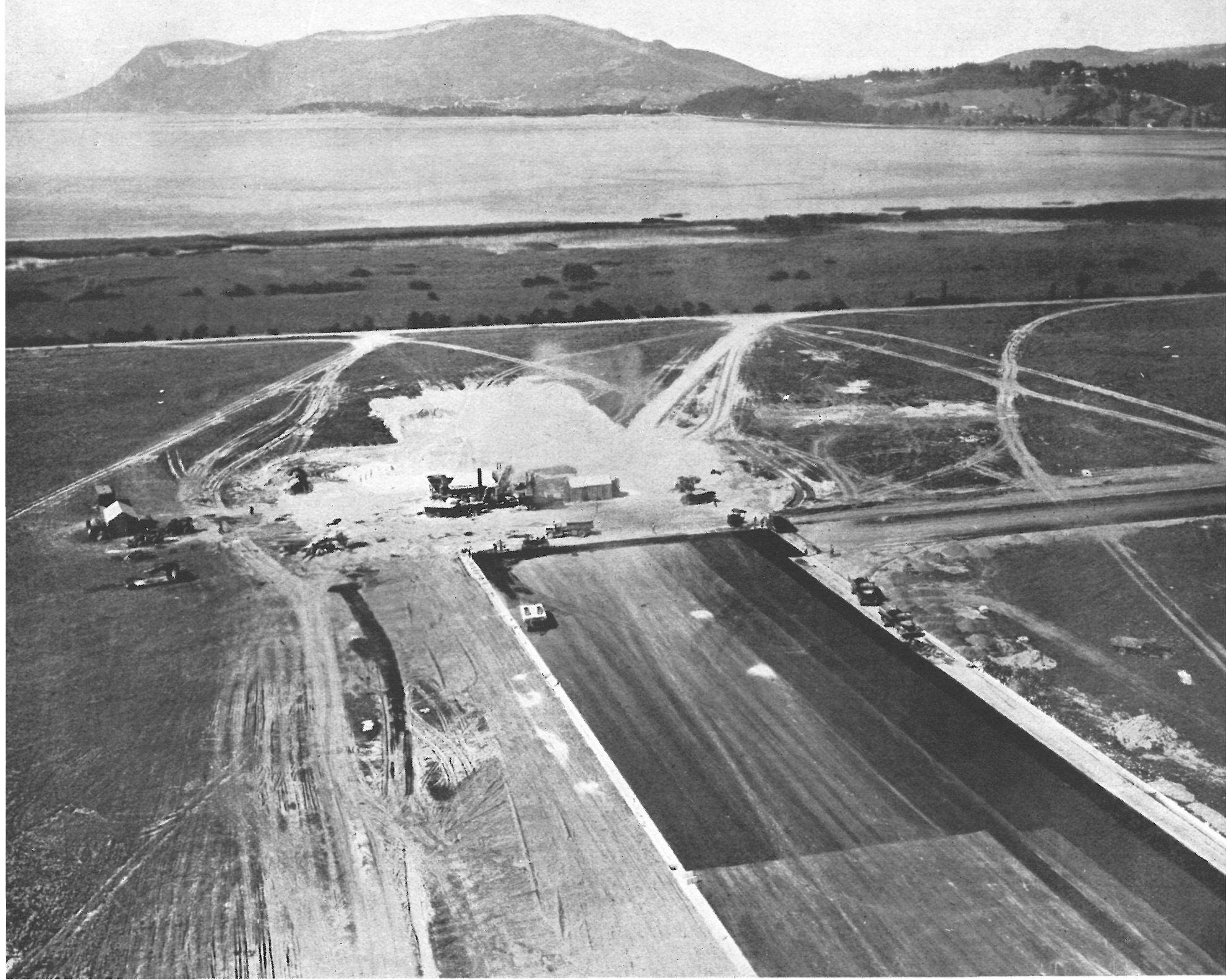

\section{Cimiento de la pista}

La sub-base de las pistas está constituida por una primera capa, de $43 \mathrm{~cm}$ de espesor medio, formada por materiales dragados del río, colocada con topadora y compactada con un cilindro de cuatro ruedas neumáticas, lastrado para un peso total de 60 toneladas. Sobre esta capa se aplicó otra, de $30 \mathrm{~cm}$ de espesor, del mismo material, pero compactada con el cilindro lastrado para 160 toneladas. La tercera capa se formó con los mismos materiales, pero en este caso cribados con anillo de $80 \mathrm{~mm}$ y compactada como la anterior.

La energía consumida por el cilindro en la primera capa fué de $150 \mathrm{t} \times \mathrm{km} \times \mathrm{m}^{3}$ y $2,5 \mathrm{t} \times \mathrm{km} \times \mathrm{m}^{3}$ en las otras dos.

Los trabajos de drenaje se realizaron simultáneamente. Terminada esta preparación general, se procedió a hormigonar un encintado que limitaba el perímetro de las pistas, así como los conductos de los cables correspondientes al balizamiento.

\section{Firme de la pista}

Después de recebar la última capa con gravilla y arena, se procedió a impregnarla con un betún de $10 / 15$ de penetración, a razón de $1,5 \mathrm{~kg} / \mathrm{m}^{2}$.

La base del firme está constituída por un espesor de $12,5 \mathrm{~cm}$ de hormigón asfáltico preparado caliente. Se estudió la posibilidad de mezclar en frío, pero para una misma seguridad el espesor debía ser de $15 \mathrm{~cm}$. Causa que motivó la elección de la vía fría. 
El firme propiamente dicho se realizó en dos capas: una de $7,5 \mathrm{~cm}$ de espesor de hormigón bituminoso muy denso y otra de rodadura de $5 \mathrm{~cm}$ de hormigón asfáltico de alta calidad.

Los áridos procedentes del dragado del lecho del río se lavaron y trituraron convenientemente. El material machacado daba una mezcla de 0 a $20 \mathrm{~mm}$; la arena natural cribada era de 0 a $5 \mathrm{~mm}$, y a estos materiales les complementaban otros procedentes de áridos machacados de cantera caliza, de los que se obtenía arena dura calcárea de 0 a $3 \mathrm{~mm}$. La harina utilizada como "filler" era cal hidráulica. El betún puro empleado era de 80/100 de penetración.

La dosificación de materiales que presentaba condiciones óptimas de resistencia y compacidad fué:

\section{Materiales}

Aridos a granel $0 / 20$.

Arena lavada.

Arena molida.

Cal.

Betún 80/100.

$\begin{array}{lc}\text { Firme } & \begin{array}{c}\text { Capa } \\ \text { de rodadura } \\ (\%)\end{array} \\ (\%) \\ 50 & 47 \\ 35 & 26 \\ 15 & 25 \\ - & 2 \\ 5,3 & 6,55\end{array}$

Esta dosificación es el resultado de las directivas seguidas por el laboratorio Marshall, de Mississipi (EE. UU.). El control en obra se realizó con un laboratorio móvil o furgoneta al objeto preparada.
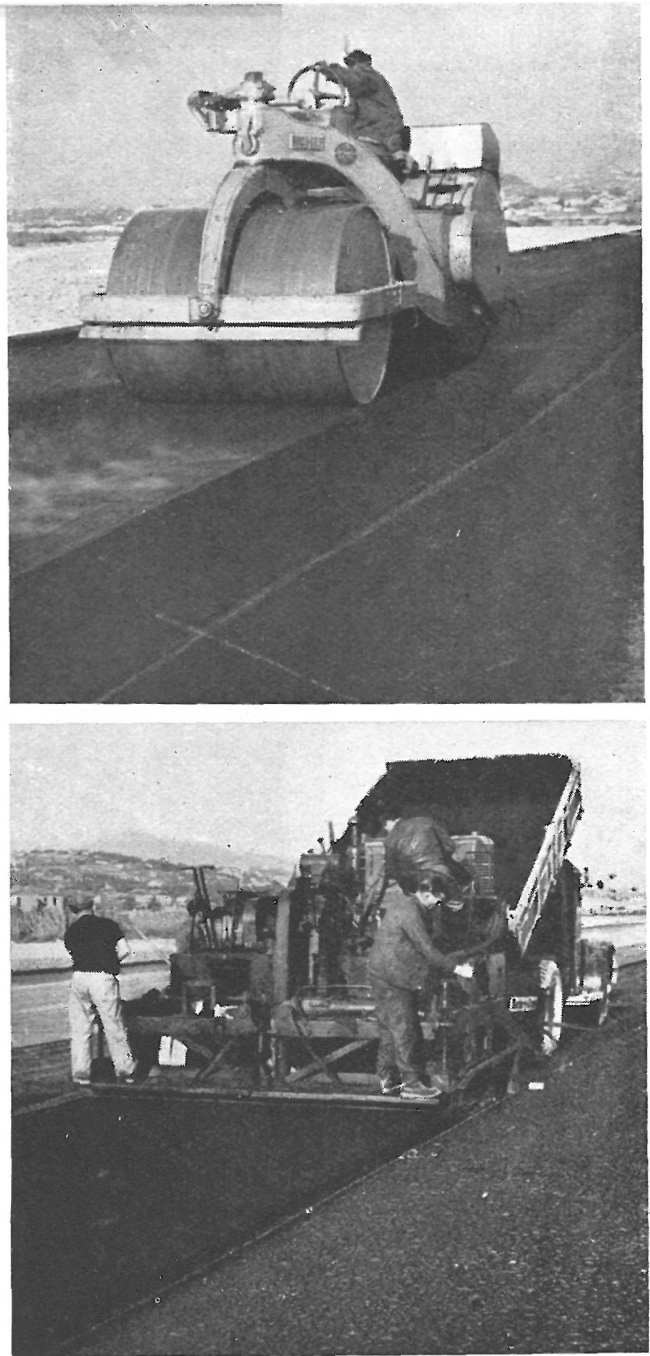

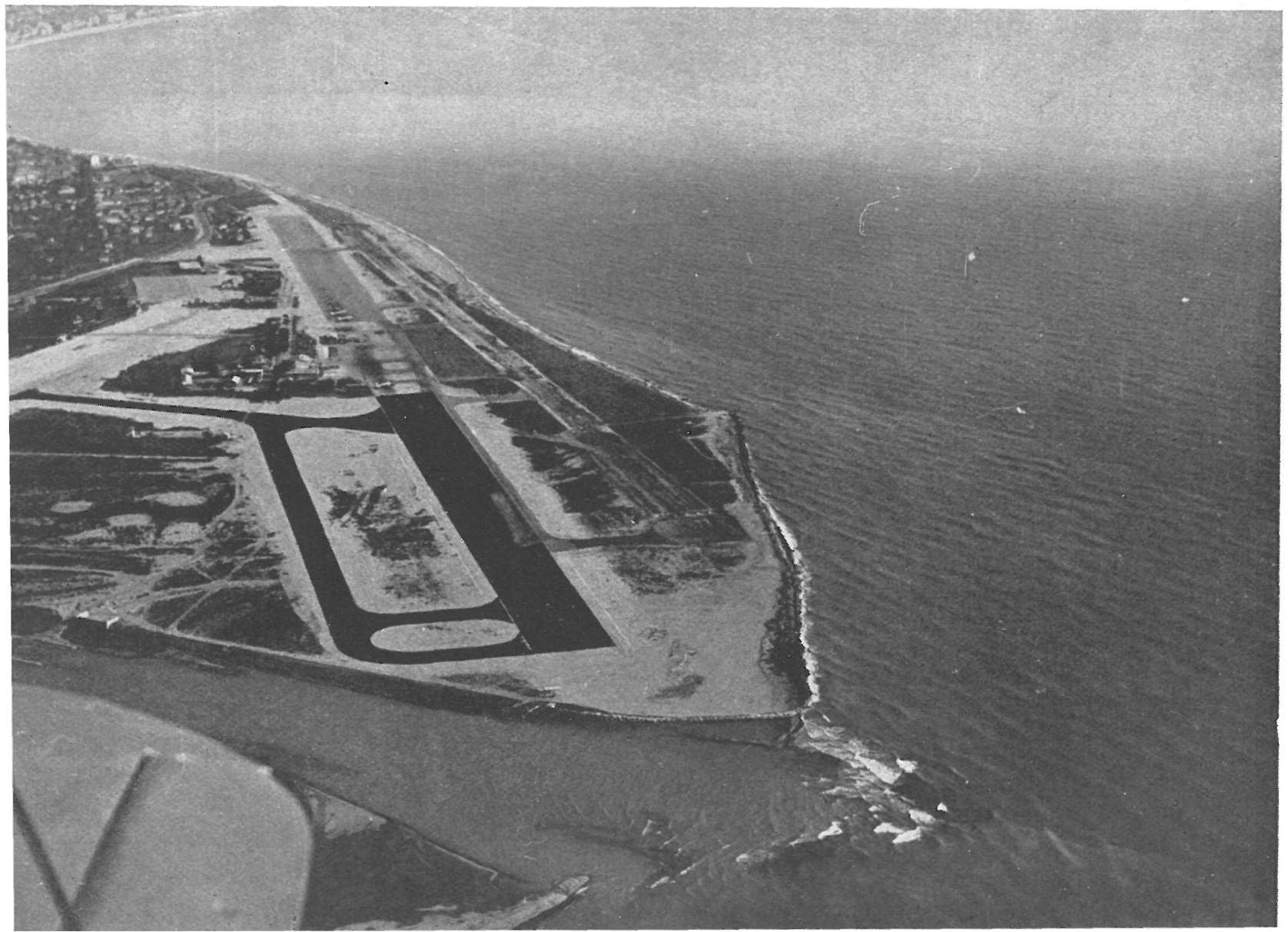


Laboratorio móvil, para ensayos físicos, montado sobre una furgoneta.

Central Barber Greene de una capacidad de $200 \mathrm{t} / \mathrm{h}$ de hormigón as fáltico.

Cargando materiales en el aeropuer-

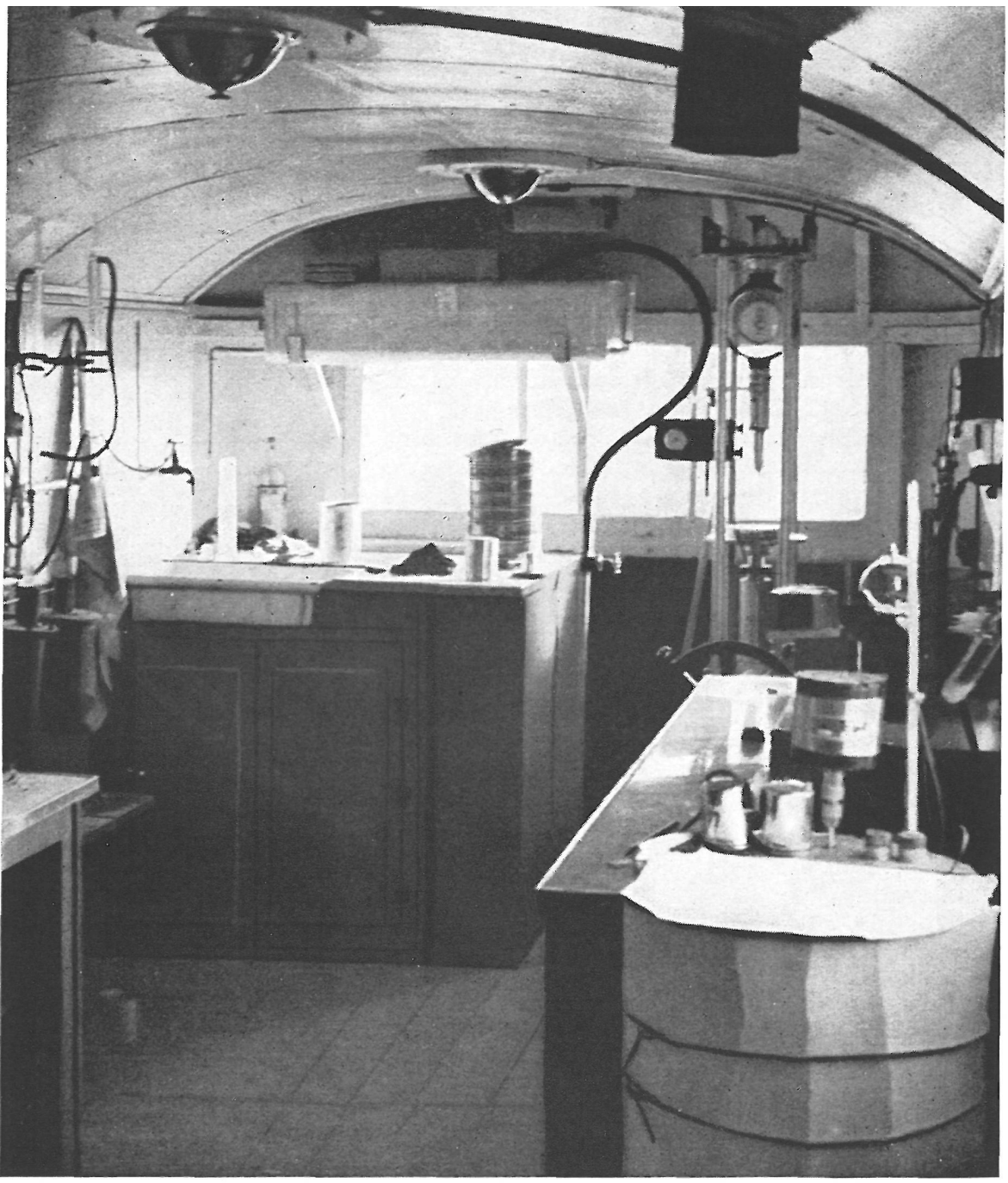

to de Niza.
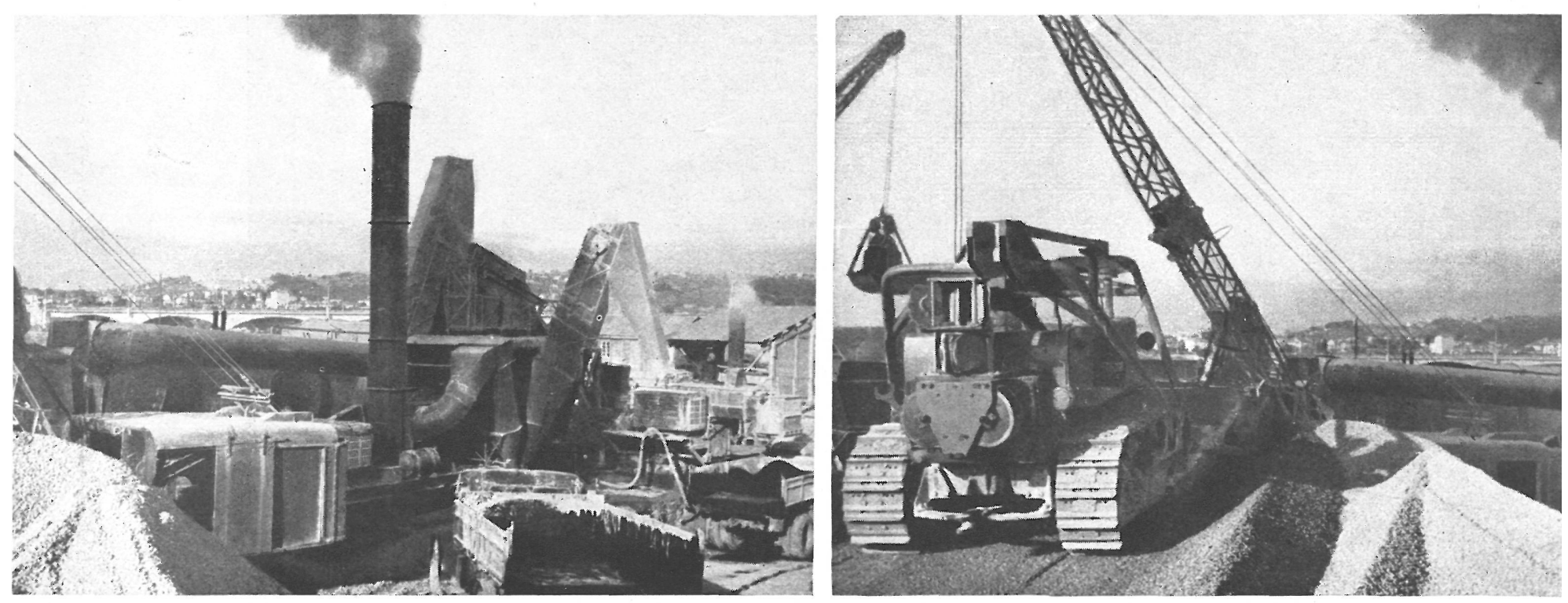
La central empleada para la fabricación del hormigón asfáltico es tipo Barber Greene, de $100 \mathrm{t} / \mathrm{h}$ de rendimiento y de producción continua. La dosificación del asfalto y áridos se hace volumétricamente por medio de cintas transportadoras que pasan por debajo de aberturas que se pueden regular a voluntad, lo que le da el carácter de continuidad a la instalación.

Esta instalación se subdivide en los órganos siguientes:

a) una tolva tipo Colas (nombre de la empresa constructora) de tres compartimientos que desbasta los áridos en tres tamaños;

b) un secadero rotatorio de áridos que utiliza un mechero de fueloil, lo quema en forma de vapor a presión y consigue una temperatura de $140^{\circ} \mathrm{C}$;

c) un recuperador de finos, compuesto por un ventilador aspirador en el secadero, y dispositivos para recoger los finos arrastrados por el vapor de agua;

d) un sistema de cribado de áridos secos con tamices vibrantes que separa los áridos en cuatro tamaños: arenas, granos tipo-arroz y dos clases de gravilla. Las cuatro tolvas del sistema vierten sobre cintas que descargan para formar la granulometría previamente estudiada;

e) un alimentador de harina de cal o «filler» en la mezcla de áridos, y

f) una hormigonera de paletas provista de una rampa de pulverización de betún, dosificado por medio de una bomba que se halla siempre en carga.

El conjunto de esta instalación es accionado por dos motores de 145 caballos. La central dispone de otros órganos auxiliares para la producción de calor, almacenamiento de betún y ufiller», y calentamiento seguido de agitación del betún.

\section{Maquinaría auxiliar para la ejecución}

a) Dos acabadoras Barber Greene que esparcen y compactan el hormigón asfáltico que los camiones transportan aún en caliente; $\mathrm{y}$

b) Seis cilindros lisos, de 4 a 12 toneladas, de los que tres son trícidos y los otros en tándem.

Las temperaturas en los distintos estados de la preparación se pueden escalar como sigue:

\section{Durante el proceso de fabricación}

Aridos a la salida del secadero $140^{\circ} \mathrm{C}$.

Betún a la salida de la cuba $150^{\circ} \mathrm{C}$.

\section{Al aplicarlo en obra}

A la salida de la hormigonera $130^{\circ} \mathrm{C}$.

A la salida de los camiones $120^{\circ} \mathrm{C}$.

Bajo el cilindro de 80 a $100^{\circ} \mathrm{C}$.

La producción media horaria calculada para la media del conjunto de tajos era de 85 toneladas/hora. Algunos días, la producción en punta fué de 1.000 toneladas/hora. Como prácticamente se mejoraron los rendimientos teóricos, el plazo de terminación fué más corto y la calidad del trabajo francamente satisfactoria.

El control de la obra terminada se llevó a efecto, por un lado, valiéndose de probetas ensayadas por el contratista en su laboratorio móvil. 
y, por el otro, en el laboratorio de Ponts et Chaussées. Los resultados de estos ensayos se pueden resumir asi:

$\begin{array}{ccc}\text { Designación } & \text { Caracteristicas } & \text { Caracteristicas } \\ \text { exigidas } & \text { comprobadas } \\ & \% & \%\end{array}$

En el firme:

$\begin{array}{ll}\text { Compacidad. } & \text { Superior al } 85 . \\ \text { Coeficiente } & \\ \text { Viágrafo. } & \text { Inferior al } 10 .\end{array}$

Capa de rodadura:

$\begin{array}{llc}\text { Compacidad. } & \text { Superior al } 94 . & 2,18 \\ \text { Coeficiente } & & \\ \text { Viágrafo. } & \text { Inferior al } 5 . & 90 \text { a } 93\end{array}$

Una de las fotografías adjuntas, de la pista del aeródromo de Chambéry-Aix-Savoie, representa una situación muy similar a lo que se ha hecho en Niza.

\section{Auropistas}

Recientemente ha entrado en servicio en Francia una central hormigonera de betún, tipo Barber Greene, de 200 toneladas de producción horaria, o, lo que es lo mismo, de 16.000 a $24.000 \mathrm{~m}^{2}$ de revestimiento por jornada de ocho horas. Es un modelo reciente y muy potente, del que sólo hay un ejemplar actualmente en Europa.

Entre las vías francesas que merecen particular mención se halla la salida de París por el Este. Esta autopista, llamada del Este, ha sido construída sobre un antiguo canal, desecado y rellenado, que unía el río Marne al Sena entre Joinville y Charenton. No existía otra solución viable que permitiese el ensanchamiento de la carretera, ya que, de no ser asi, se tenía que derribar un número considerable de casas de habitación.

Para el relleno del canal han sido necesarios unos $500.000 \mathrm{~m}^{3}$ de escombro. La determinación de los materiales de relleno ha sido motivo de preocupación e investigación. El transporte se hizo por camión, que, distribuyéndose conforme a un orden, extendióse con niveladoras mecánicas, dotados de la humedad prevista y compactados con cilindros de ruedas neumáticas.

Los caminos franceses se han venido realizando con gran rapidez, ya que en seis meses se han colocado en obra unos $58.000 \mathrm{~m}^{3}$ de materiales compactados para sub-base, capa de filtrante y base. En estos materiales van incluidas unas $10.500 \mathrm{t}$ de áridos envueltos de betún, $3.600 \mathrm{t}$ de emulsión ácida, $2.100 \mathrm{t}$ de aglomerante de trabazón y 4.800 t de hormigón asfáltico.

Actualmente, Francia sólo cuenta con $70 \mathrm{~km}$ de autopistas, pero se ha previsto un plan decenal para ampliar dicha cifra a $2.000 \mathrm{~km}$, con un gasto de unos 30.000 millones de pesetas. Como esta cifra rebasa la posibilidad estatal, se ha pensado dar este trabajo a la iniciativa privada, es decir, que las autopistas se amortizarán con un impuesto directo de peaje a los usuarios.

El plan comprendería los itinerarios siguientes: París-Niza; ParísLille-frontera belga; París-Normandía y Lyon-Ginebra.

Parte del trazado París-Niza ha empezado ya en los trozos EsterelCôte d'Azur y Vienne-Valence, en el valle del Ródano. El recorrido ParísNiza comprende la gran vía Lyon-Marsella, subdividida en tres trozos: a) Lyon-Vienne, de $30 \mathrm{~km}$; b) Vienne-Aix en Provence, de $260 \mathrm{~km}$, que se conoce con el nombre de pista de unión, y c) Marsella a Bouc Bel Air, ya construído, de $15 \mathrm{~km}$ de longitud. El trozo Bel-Air a Aix, de $15 \mathrm{~km}$ de longitud, se va a emprender rápidamente. 


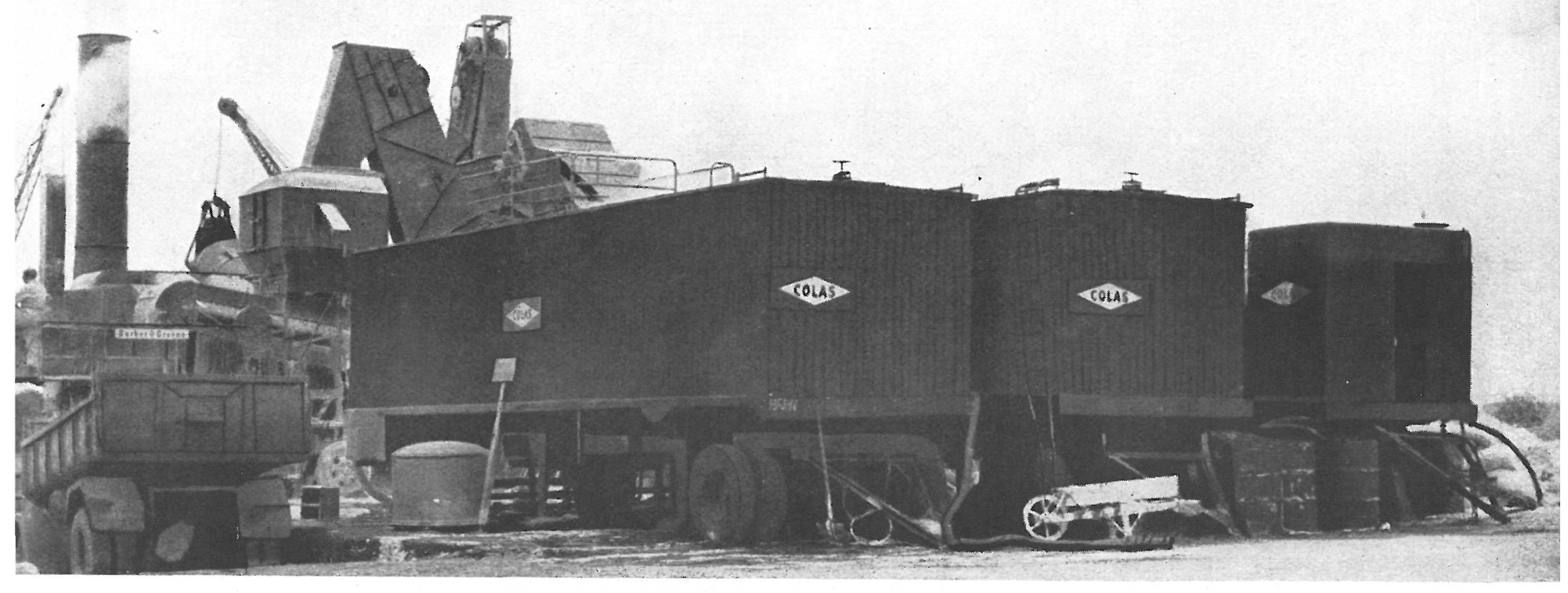

Depósitos auxiliares de la central de gran capacidad de la casa Barber Greene.

Vista próxima de la central Barber Greene.

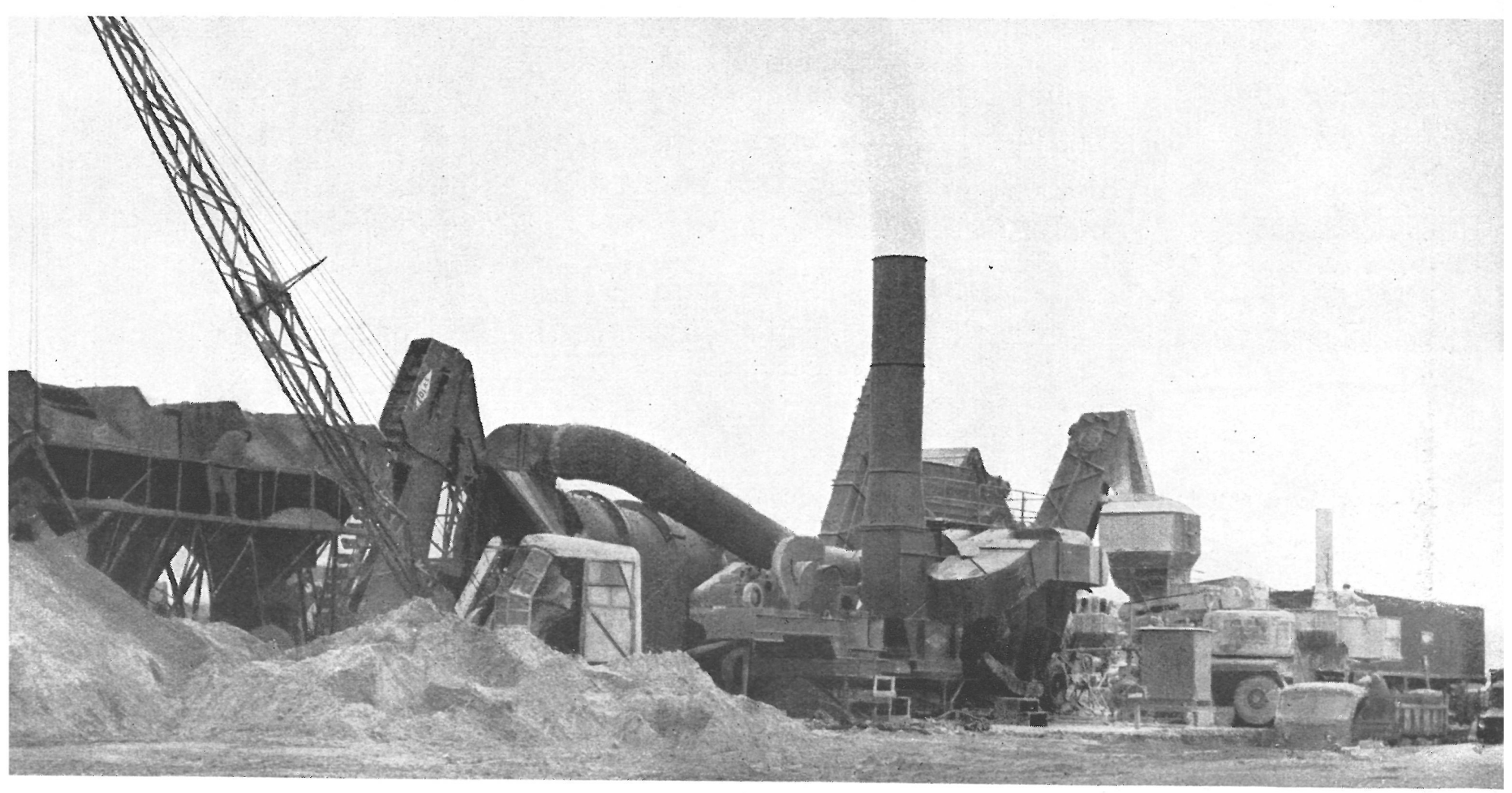




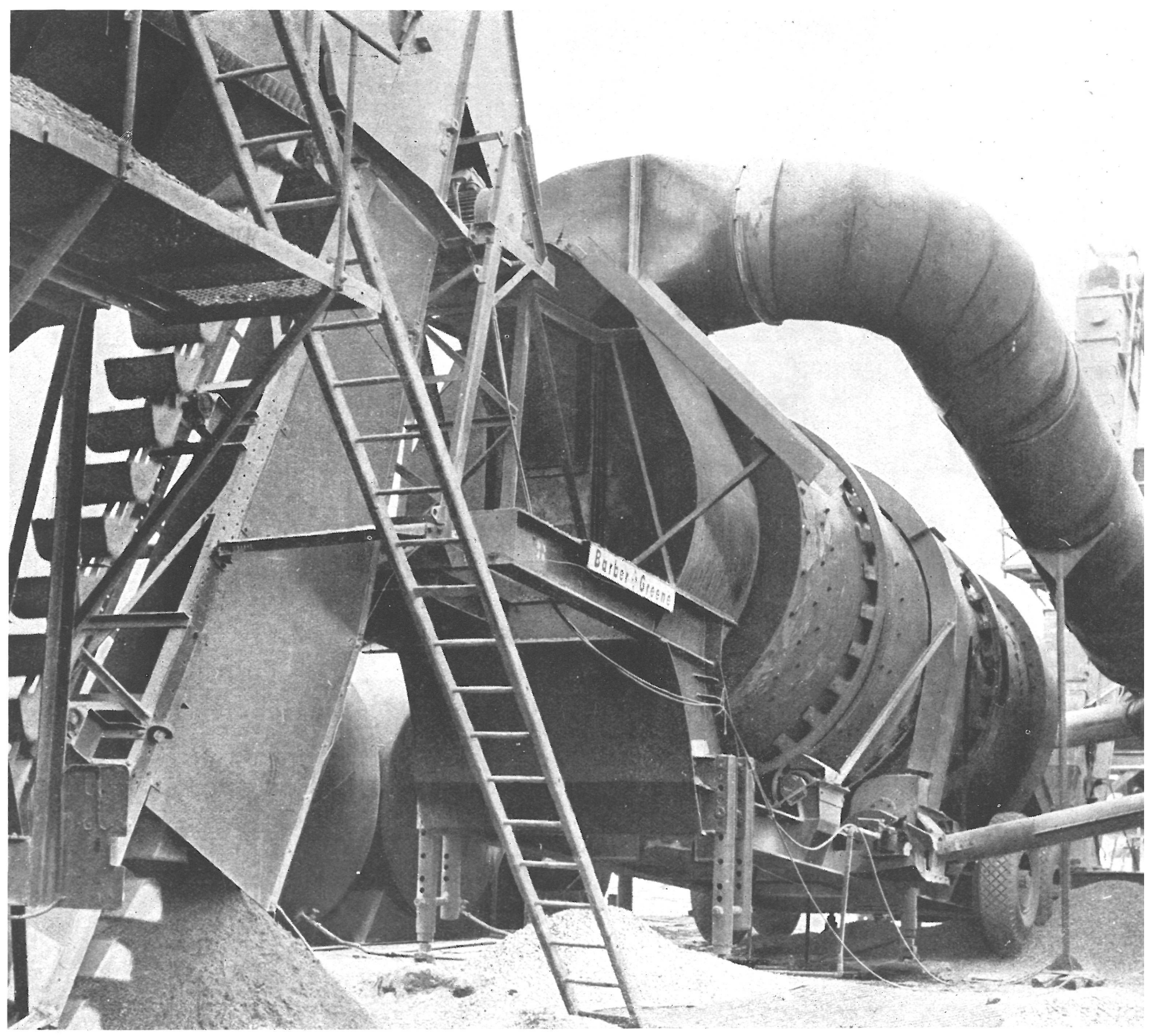

Fotos: SHELL BERRE Y HAUSS

La autopista de unión entre Vienne y Aix se subdividirá en tres trozos: el primero, de $63 \mathrm{~km}$ de longitud, se pondrá probablemente en servicio en 1961. En este trozo se cree que el kilómetro de vía costará unos 14 millones de pesetas. El derecho de peaje previsto es de 0,25 pesetas por kilómetro para los vehículos de turismo y 0,80 pesetas para los camiones y autobuses.

Finalmente, existe un proyecto de autopista, que sale por el suroeste de París, cuyo trazado aprovecharía la plataforma del ferrocarril de Gallardon, en el trozo París-Chartres, que no ha sido utilizado todavía.

J. J. U.

I NFORMES DE LA CONSTRUCCION 95 